Journal of Pharmacy Practice and Community Medicine.2018, 4(1s):S73-S78 • http://dx.doi.org/10.5530/jppcm.2018.1s.24

e-ISSN: 2455-3255

\title{
National Survey of Pharmacy Leadership at Ministry of Health in Saudi Arabia: Practice Management
}

\author{
Yousef Ahmed Alomi ${ }^{* 1}$, Modhi Abdulmohsen Albaz ${ }^{2}$, Wejdan Fawzan AlMuhraj ${ }^{2}$, Mashael Yasser AlKharji², \\ Norah Rushud Alshuraym² \\ ${ }^{1}$ The Past General Manager of General Administration of Pharmaceutical Care and Head, National Clinical pharmacy, and \\ pharmacy practice and Pharmacy $R$ and D Administration, Ministry of Health, Riyadh, KSA. \\ ${ }^{2}$ Clinical Pharmacy Staff, General Administration of Pharmaceutical Care, Ministry of Health, Riyadh 11392, SAUDI ARABIA.
}

\section{Received: 13 December 2017; \\ Accepted: 28 February 2018 \\ *Correspondence to: \\ Dr. Yousef Ahmed Alomi,}

The Past General Manager of General Administration of Pharmaceutical Care Head, National Clinical pharmacy, and pharmacy practice Head, Pharmacy $R$ and $D$ Administration Ministry of Health, P.O.BOX 100, Riyadh 11392, Riyadh, SAUDI ARABIA. Riyadh, Saudi Arabia.

Email:yalomi@gmail.com

Copyright: (c) the author(s),publisher and licensee Indian Academy of Pharmacists. This is an open-access article distributed under the terms of the Creative Commons Attribution Non-Commercial License, which permits unrestricted non-commercial use, distribution, and reproduction in any medium, provided the original work is properly cited.

\begin{abstract}
Objective: To explore the national survey of pharmacy leadership at the Ministry of Health with emphasis on pharmacy practice. Methods: It is a ninety days cross-sectional national survey of pharmacy leadership practice at $\mathrm{MOH}$ hospitals. The survey modified from self-assessment of 360 leadership and with pharmacy leadership literature. It consisted of a demographic section, leadership pathway, and fifty-three leadership questions. It contained selected eighteen leadership skills of 360 leadership self-assessment. The leadership skills included Achievement, Goals, Flexibility, Feedback, Excellence, Empowering Others, Emotional Intelligence, Decision Making, Developing Others, Cultural Awareness, Continual Improvement, Communication Skills, Coworker Development, Leading the Change Needed, Attitude, Analytical, Administrative Skill, and Action. This survey distributed to all leadership at $\mathrm{MOH}$ hospital pharmacies in Kingdom of Saudi Arabia. All analysis is done through the survey monkey system. The survey divided into for several parts for analysis, and discussion. Part one: practice management, part two: planning and organizations, part three: communications strategies, part four: problem-solving and decision making, part five: performances management, part six; working environment, and part seven: professional development. The study explored the part number one; National Survey of Pharmacy leadership: practice management. Results: The survey distributed to one hundred hospitals, the response rate, was forty-two hospitals (42\%) with seventy-pharmacy leaders. The gender distribution of responders was Male $43(63.24 \%)$ and female $25(36.76 \%)$ while the nationality was Saudi $69(98.57 \%)$ and non-Saudi 1 (1.43\%). The average score Aspects before handling the position was 2.45 (49\%) with the highest score was received pharmacy administration orientation 2.57 (51.4\%), and the lowest score was received pharmacy administration training courses before handling the positions 2.29 (45.8\%). The most sources of gaining skills in pharmacy leadership were life experiences 51 (72.86\%) and on job training $29(41.43 \%)$. The average score of administration skills that had pharmacy leaders was 3.63 (72.6\%) with the highest score of Communication skills 4.15 (83\%), and the lowest score of administration skills was Marketing skills 2.62 (52.4\%). Most of the pharmacy leaders had is no incremental of the salary of current positions $44(67.69 \%)$, and most of them got 1-5\% only if existed. The majority of pharmacy leaders 29 (43.28\%) planned to quit the current position. Conclusion: The pharmacy leadership had low satisfaction at a healthcare organization in Saudi Arabia. Targeting of established very comprehensive leadership program with an emphasis on pharmacy leadership is a requirement for Ministry of Health institutions leads to improve the pharmacy services offered to the patients.
\end{abstract}

Key word: Pharmacy leadership, Practice management, Ministry of health, Saudi arabia.

\section{INTRODUCTION}

The essential core of pharmaceutical care is a pharmacist. The group of pharmacists needs a leader to implement the services inside the healthcare organization. The American Society of Health-System Pharmacist and other pharmacy organizations released several publications in pharmacy leadership. ${ }^{[1-7]}$ Also, the ASHP had several programs of pharmacy leadership including courses or residency programs. The general administration of pharmaceutical care released several program and services of pharmacy administration that's support pharmacy leaders in their practice. ${ }^{[8]}$ It included but not limited to the following: pharmacist job satisfaction, Pharmacy staff requirements standard for hospitals and primary healthcare centers, hospital and primary care center pharmacist competency, and patient satisfaction with pharmacy services. ${ }^{[9-12]}$ Also, the pharmacy administration conducted several courses of pharmacy administration skills and leadership skills for the pharmacist. Several publications discussed leadership in pharmacy practice as general and pharmacy administration. ${ }^{[13-17]}$ Others studies conducted to measure the level and status of pharmacy leadership in several counties. ${ }^{[18-23]}$ Most of the studies focused pharmacy leadership with students or trainees, but the investigation with pharmacist practitioner were few. ${ }^{[24-27]}$ Also, $t$ is desperate to find investigation inside Saudi Arabia or Gulf and Middle East counties about pharmacy leadership or studies utilized 360-self assessment measurement. The objective of the study to explore the national survey of pharmacy leadership with the emphasis on practice management. 


\section{METHODS}

It is a ninety days cross-sectional national survey of pharmacy leadership practice at $\mathrm{MOH}$ hospitals. The survey modified from self-assessment of 360 leadership and with pharmacy leadership literature. It consisted of a demographic section, leadership pathway, and fifty-three leadership questions. It contained selected eighteen leadership skills of 360 leadership self-assessment. ${ }^{[28]}$ Of The leadership skills included Achievement, Goals, Flexibility, Feedback, Excellence, Empowering Others, Emotional Intelligence, Decision Making, Developing Others, Cultural Awareness, Continual Improvement, Communication Skills, Coworker Development, Leading the Change Needed, Attitude, Analytical, Administrative Skill, and
Action. The questions consisted of open and closed questions. The 5-points or 3-point Likert response scale system used. This survey distributed to all leadership at $\mathrm{MOH}$ hospital pharmacies in Kingdom of Saudi Arabia. It included general director of pharmacy at $\mathrm{MOH}$ and regions, the directors of pharmacy and supervisor at $\mathrm{MOH}$ hospital pharmacies. The electronic format of the survey through the survey monkey system and distributed through emails. A reminder e-mail containing a link to the website forwarded two weeks after. All analysis is done through the survey monkey system. The survey divided into for several parts for analysis, and discussion. Part one: practice management, part two: planning and organizations, part three: communications strategies, part four: problem-solving and decision making,

\section{Table 1: Demographic information of pharmacy leaders.}

\begin{tabular}{|c|c|c|c|c|c|}
\hline Gender & Response N & Response \% & Complete pharmacy residency & Response N & Response \% \\
\hline Male & 43 & $63.24 \%$ & Yes & 10 & $14.93 \%$ \\
\hline Female & 25 & $36.76 \%$ & No & 57 & $85.07 \%$ \\
\hline Answered question & 68 & & Answered question & 67 & \\
\hline Skipped question & 2 & & Skipped question & 3 & \\
\hline Nationality & Response N & Response \% & $\begin{array}{l}\text { Do you have Board of Pharmaceutical } \\
\text { Specialty }\end{array}$ & Response N & Response \% \\
\hline Saudi & 69 & $98.57 \%$ & Board Certified Ambulatory Care Pharmacist & 1 & $1.54 \%$ \\
\hline Non- Saudi & 1 & $1.43 \%$ & Board Certified Critical Care Pharmacist & 1 & $1.54 \%$ \\
\hline Answered question & 70 & & Board Certified Pharmacotherapy Specialists & 2 & $3.08 \%$ \\
\hline Skipped question & 0 & & Non & 62 & $95.38 \%$ \\
\hline \multicolumn{3}{|c|}{ Academic Qualification (s } & Answered question & 65 & \\
\hline 18 to 24 & 0 & $0.00 \%$ & Skipped question & 5 & \\
\hline 25 to 34 & 30 & $44.12 \%$ & Total years of current position & Response N & Response \% \\
\hline 35 to 44 & 26 & $38.24 \%$ & General Manager of Pharmaceutical care & 5 & $7.58 \%$ \\
\hline 45 to 54 & 10 & $14.71 \%$ & Manager of Pharmaceutical care at region & 1 & $1.52 \%$ \\
\hline 55 to 64 & 1 & $1.47 \%$ & Director of Hospital pharmacy & 24 & $36.36 \%$ \\
\hline 65 to 74 & 1 & $1.47 \%$ & Supervisor of pharmacy units & 33 & $50.00 \%$ \\
\hline 75 or older & 0 & $0.00 \%$ & Director of Primary care center pharmacy & 3 & $4.55 \%$ \\
\hline Answered question & 68 & & Answered question & 66 & \\
\hline Skipped question & 2 & & Skipped question & 4 & \\
\hline \multicolumn{3}{|c|}{ Academic Qualification (s } & Total years worked as a Pharmacist & Response $\mathbf{N}$ & Response \% \\
\hline Diploma Pharmacy & 7 & $10.29 \%$ & $<3$ & 9 & $13.24 \%$ \\
\hline Bsc. Pharm & 44 & $64.71 \%$ & $3-5$ & 13 & $19.12 \%$ \\
\hline M.S & 9 & $13.24 \%$ & $6-10$ & 13 & $19.12 \%$ \\
\hline Msc. Clinical Pharmacy & 4 & $5.88 \%$ & $11-15$ & 14 & $20.59 \%$ \\
\hline Pharm.D. & 11 & $16.18 \%$ & $>15$ & 19 & $27.94 \%$ \\
\hline Ph.D & 0 & $0.00 \%$ & Answered question & 68 & \\
\hline MBA & 4 & $5.88 \%$ & Skipped question & 2 & \\
\hline Pharmacy Residency (R1) & 2 & $2.94 \%$ & Years of experience in administrative work & Response N & Response \% \\
\hline Pharmacy Residency (R2) & 2 & $2.94 \%$ & Less than one year & 10 & $14.29 \%$ \\
\hline Fellowship & 1 & $1.47 \%$ & $1-3$ years & 18 & $25.71 \%$ \\
\hline Other (please specify) & 6 & $8.82 \%$ & $4-5$ years & 13 & $18.57 \%$ \\
\hline Answered question & 68 & & $6-10$ & 14 & $20.00 \%$ \\
\hline \multirow[t]{3}{*}{ Skipped question } & 2 & & More than ten years & 15 & $21.43 \%$ \\
\hline & & & Answered question & 70 & $14.29 \%$ \\
\hline & & & Skipped question & 0 & \\
\hline
\end{tabular}


part five: performances management, part six; working environment, and part seven: professional development. The study explored the part number one; National Survey of Pharmacy leadership: practice management

\section{RESULTS}

The survey distributed to one hundred hospitals, the response rate, was forty-two hospitals $(42 \%)$ with seventy-pharmacy leaders. The majority of the hospital bed size (200-299) was 16 (24.24\%) followed by nine (13.64\%) bed size (300-399) and eight (12.12\%) more than bed size ( $=$ or $>600)$. The number of hospitals accredited by the Saudi Central Board of Hospitals Accreditation (CIBAHI) was $36(76.60 \%)$ while 22 hospitals $(46.81 \%)$ accredited by USA International Joint Commission and CIBAHI and $11(23.40 \%)$ accredited by the Saudi Commission of Healthcare specialties. The gender distribution of responders was Male 43 (63.24\%) and female $25(36.76 \%)$ while the nationality was Saudi $69(98.57 \%)$ and non-Saudi $1(1.43 \%)$. The majority of responders were in the age range (25-34) years $30(55.12 \%)$ and (35-44 years) $26(38.24 \%)$. The academic qualifications

\section{Table 2: Demographic hospital information.}

\begin{tabular}{|c|c|c|}
\hline Number of beds at hospital & Response $\mathbf{N}$ & Response \% \\
\hline$<50$ & 6 & $9.09 \%$ \\
\hline $50-99$ & 5 & $7.58 \%$ \\
\hline $100-199$ & 7 & $10.61 \%$ \\
\hline $200-299$ & 16 & $24.24 \%$ \\
\hline 300-399 & 9 & $13.64 \%$ \\
\hline $400-599$ & 4 & $6.06 \%$ \\
\hline More than or equal 600 & 8 & $12.12 \%$ \\
\hline Medical City & 7 & $10.61 \%$ \\
\hline $\begin{array}{l}\text { Regional Drug Information Centers at } \\
\text { (General Health Affairs Directorate) }\end{array}$ & 4 & $6.06 \%$ \\
\hline \multicolumn{3}{|l|}{ Answered question: 70 and skipped : 0} \\
\hline The hospital accreditation & $\begin{array}{l}\text { Response } \\
\text { Count }\end{array}$ & $\begin{array}{l}\text { Response } \\
\text { Percent }\end{array}$ \\
\hline CIBAHI & 36 & $76.60 \%$ \\
\hline $\begin{array}{l}\text { Saudi Commission of Healthcare } \\
\text { specialties }\end{array}$ & 11 & $23.40 \%$ \\
\hline $\mathrm{JCl}$ & 22 & $46.81 \%$ \\
\hline Canada & 2 & $4.26 \%$ \\
\hline ASHP & 0 & $0.0 \%$ \\
\hline ACCP & 1 & $5.0 \%$ \\
\hline Non & 4 & $20.0 \%$ \\
\hline \multicolumn{3}{|c|}{ Answered question: 47 and skipped question 23} \\
\hline
\end{tabular}

\begin{tabular}{|c|c|c|}
\hline Answer Choices & Response N & Response \% \\
\hline Life Experiences & 51 & $72.86 \%$ \\
\hline Administration Short course $1-5$ days & 22 & $31.43 \%$ \\
\hline Administration long training 1-3 months & 9 & $12.86 \%$ \\
\hline Master of Business Administration (MBA) & 5 & $7.14 \%$ \\
\hline On Job training & 29 & $41.43 \%$ \\
\hline Leadership in professional organization & 10 & $14.29 \%$ \\
\hline Residency program & 4 & $5.71 \%$ \\
\hline Other (please specify) & 5 & \\
\hline
\end{tabular}

of responders were BSc. Pharm 44 (64.71\%) followed by Mater degree $9(13.24 \%)$ and Diploma Pharmacy 7 (10.29\%). Of those only 10 (14.93\%) completed a residency program in pharmacy administrations and four $(4.16 \%)$ had completed board of pharmaceutical specialties. The majority of responders worked as a supervisor of the unit at hospital pharmacy $33(50 \%)$ or director of pharmacy $24(36.36 \%)$. Of those they had experiences as pharmacist more than ten years $33(47.14 \%)$ and had administrative work one to three years' experience $18(25.71 \%)$ and more than ten years were $15(21.43 \%)$ as explored in Table 1 and Table 2 . The average score Aspects before handling the position was $2.45(49 \%)$ with the highest score was received pharmacy administration orientation 2.57 (51.4\%), and the lowest score was received pharmacy administration training courses before handling the positions $2.29(45.8 \%)$ as explored in Table 3. The most sources of gaining skills in pharmacy leadership were life experiences $51(72.86 \%)$ and on job training $29(41.43 \%)$, as explores in Table 4 . The average score of administration skills that had pharmacy leaders was 3.63 (72.6\%) with the highest score of Communication skills $4.15(83 \%)$, and the lowest score of administration skills was Marketing skills $2.62(52.4 \%)$ as explores in Table 5. The most advantages of pharmacy leadership position were no night shift $29(41.43 \%)$ and nothing-useful 21 (30.00\%) while the most disadvantaged of pharmacy leadership position were High workload $42(60 \%)$ and significant responsibility without benefit $37(52.86 \%)$ as explored in Table 6. Most of the pharmacy leaders had is no incremental of the salary of current positions 44 (67.69\%), and most of them got 1-5\% only if existed. The majority of pharmacy leaders $29(43.28 \%)$ planned to quit the current position as explored in Table 7.

\section{DISCUSSIONS}

The Ministry of Health started the last strategic health care plan in 2010 with several achievements. ${ }^{[29]}$ During that period, the Minister of Health had an annual regular meeting of healthcare leadership. The Minister led the meeting, and each leader deviled presentation related to their specialty and

\section{Table 3: Aspects of handling the position.}

\begin{tabular}{|c|c|c|c|c|c|c|c|c|c|c|c|c|}
\hline Answer Options & \multicolumn{2}{|r|}{5} & \multicolumn{2}{|r|}{4} & \multicolumn{2}{|r|}{3} & \multicolumn{2}{|r|}{2} & \multicolumn{2}{|r|}{1} & \multirow{2}{*}{$\begin{array}{c}\text { Average } \\
2.29\end{array}$} & \multirow{2}{*}{$\begin{array}{c}\text { Response } \mathbf{N} \\
69\end{array}$} \\
\hline $\begin{array}{l}\text { Did you receive any pharmacy administration courses or } \\
\text { training before handing your position }\end{array}$ & 10 & $14.49 \%$ & 7 & $10.14 \%$ & 8 & $11.59 \%$ & 11 & $15.94 \%$ & 33 & $47.83 \%$ & & \\
\hline $\begin{array}{l}\text { Did you receive any general management courses or training } \\
\text { before handing your position }\end{array}$ & 10 & $14.49 \%$ & 4 & $5.80 \%$ & 12 & $17.39 \%$ & 15 & $21.74 \%$ & 28 & $40.58 \%$ & 2.43 & 69 \\
\hline $\begin{array}{l}\text { Did you receive any orientation pharmacy administration } \\
\text { before handling your position }\end{array}$ & 13 & $18.57 \%$ & 10 & $14.29 \%$ & 8 & $11.43 \%$ & 14 & $20.00 \%$ & 25 & $35.71 \%$ & 2.57 & 70 \\
\hline $\begin{array}{l}\text { Did you receive any inducement from previous manager or } \\
\text { supervisor during handling your position }\end{array}$ & 12 & $17.14 \%$ & 8 & $11.43 \%$ & 9 & $12.86 \%$ & 16 & $22.86 \%$ & 25 & $35.71 \%$ & 2.53 & 70 \\
\hline \multicolumn{13}{|l|}{ answered question 70 and skipped 0} \\
\hline
\end{tabular}


Table 5: The current administration skills of pharmacy leaders.

\begin{tabular}{|c|c|c|c|c|c|c|c|c|c|c|c|c|}
\hline Answer Options & & 5 & & 4 & & 3 & & 2 & & 1 & Average & Response N \\
\hline Strategic planning & 11 & $16.67 \%$ & 26 & $39.39 \%$ & 23 & $34.85 \%$ & 3 & $4.55 \%$ & 3 & $4.55 \%$ & 3.59 & 66 \\
\hline Executive planning & 9 & $13.64 \%$ & 25 & $37.88 \%$ & 18 & $27.27 \%$ & 11 & $16.67 \%$ & 3 & $4.55 \%$ & 3.39 & 66 \\
\hline Interview skills & 5 & $7.58 \%$ & 33 & $50.00 \%$ & 16 & $24.24 \%$ & 7 & $10.61 \%$ & 5 & $7.58 \%$ & 3.39 & 66 \\
\hline Presentation skills & 10 & $15.15 \%$ & 31 & $46.97 \%$ & 17 & $25.76 \%$ & 7 & $10.61 \%$ & 1 & $1.52 \%$ & 3.64 & 66 \\
\hline Leadership skills & 17 & $25.76 \%$ & 30 & $45.45 \%$ & 15 & $22.73 \%$ & 2 & $3.03 \%$ & 2 & $3.03 \%$ & 3.88 & 66 \\
\hline Communication skills & 25 & $37.88 \%$ & 31 & $46.97 \%$ & 7 & $10.61 \%$ & 1 & $1.52 \%$ & 2 & $3.03 \%$ & 4.15 & 66 \\
\hline Marketing skills & 5 & $7.69 \%$ & 10 & $15.38 \%$ & 18 & $27.69 \%$ & 19 & $29.23 \%$ & 13 & $20.00 \%$ & 2.62 & 65 \\
\hline Negotiating skills & 8 & $12.12 \%$ & 23 & $34.85 \%$ & 20 & $30.30 \%$ & 9 & $13.64 \%$ & 6 & $9.09 \%$ & 3.27 & 66 \\
\hline Meetings skills & 14 & $21.54 \%$ & 31 & $47.69 \%$ & 13 & $20.00 \%$ & 4 & $6.15 \%$ & 3 & $4.62 \%$ & 3.75 & 65 \\
\hline Time management & 7 & $10.77 \%$ & 36 & $55.38 \%$ & 17 & $26.15 \%$ & 3 & $4.62 \%$ & 2 & $3.08 \%$ & 3.66 & 65 \\
\hline Decision Making skills & 15 & $23.44 \%$ & 32 & $50.00 \%$ & 13 & $20.31 \%$ & 2 & $3.13 \%$ & 2 & $3.13 \%$ & 3.88 & 64 \\
\hline Problems solving silks & 19 & $28.79 \%$ & 35 & $53.03 \%$ & 6 & $9.09 \%$ & 3 & $4.55 \%$ & 3 & $4.55 \%$ & 3.97 & 66 \\
\hline Team building skills & 19 & $28.79 \%$ & 35 & $53.03 \%$ & 9 & $13.64 \%$ & 0 & $0.00 \%$ & 3 & $4.55 \%$ & 4.02 & 66 \\
\hline Innovation skills & 9 & $13.85 \%$ & 31 & $47.69 \%$ & 19 & $29.23 \%$ & 3 & $4.62 \%$ & 3 & $4.62 \%$ & 3.62 & 65 \\
\hline
\end{tabular}

\section{Table 6: The advantages of current pharmacy leadership position}

\begin{tabular}{|l|c|c|}
\hline Answer Choices & Response N & Response \% \\
\hline Increment salary & 15 & $21.43 \%$ \\
\hline Free administration courses & 12 & $17.14 \%$ \\
\hline Free pharmacy training courses & 10 & $14.29 \%$ \\
\hline No night shift & 29 & $41.43 \%$ \\
\hline Free inside pharmacy conference & 7 & $10.00 \%$ \\
\hline Free outside pharmacy conference & 5 & $7.14 \%$ \\
\hline Nothing & 21 & $30.00 \%$ \\
\hline Other (please specify) & 7 & \\
\hline
\end{tabular}

discussed with all leaders. The General administration of pharmaceutical care leaders at that time attended with them and delivered two presentations in two series years. The healthcare leadership meeting trains all leaders in healthcare management and communications strategies. The director of pharmacy administration had regular meetings with twenty-pharmacy leadership as directors of pharmacy services at regions. In the meeting, the pharmacy strategic plan discussed and approved, and each director deliver updated the meeting members about pharmacy performance in the region and the level of implementation of the pharmacy strategic plan and their problems and suggestions to solve them. The meeting as part of education and training proposes in addition to complete the work. The General administration of education and training development delivered several courses about leadership, including 360-degree self-assessment. The investigator tried to implement 360 tools for pharmacy leadership to explore the strength and weakness of pharmacy leaders at $\mathrm{MOH}$ hospitals and administration. The finding showed two third of the pharmacy leaders were male gender with most them Saudi this normal result because the most of our society accept the male leaders than a female one. That almost resembles what reported by Pollard, SR et al., and White, SJ et al. ${ }^{[19-20]}$ Also,

\section{The disadvantages of pharmacy leadership. position}

\begin{tabular}{|c|c|c|}
\hline Answer Choices & Response N & Response \% \\
\hline Big responsibility without benefit & 37 & $52.86 \%$ \\
\hline High workload & 42 & $60.00 \%$ \\
\hline High accountability & 21 & $30.00 \%$ \\
\hline No increment of Salary & 27 & $38.57 \%$ \\
\hline No free pharmacy training courses & 18 & $25.71 \%$ \\
\hline No free administration training courses & 20 & $28.57 \%$ \\
\hline No free pharmacy conferences & 18 & $25.71 \%$ \\
\hline Nothing & 4 & \\
\hline
\end{tabular}

the number of pharmacies had a residency program lower than what report by Pollard, SR et al., and White, SJ et al. ${ }^{[19-20]}$ that is due the pharmacy program had an insufficient position and few number of programs in Saudi Arabia. Most of the leaders in young age with most of them had a bachelor's degree and seldom finding residency training the finding expected because of our college of pharmacy graduated were bachelor pharmacy but nor most them converted to Pharm D degree. The age of Saudi leaders younger than what reported by Pollard, SR et al., and White, SJ et al. ${ }^{[19-20]}$ Because the number of pharmacists lower than what is in the USA and the time to be pharmacy leader is speedy. Most of the leaders had from 1-5 years of pharmacy administration that is the pharmacy practice development. That resembles what reported by Pollard et al., the old study while is lower than and White, SJ et al. ${ }^{[19-20]}$ That is related to time more in the USA more time to spend in the pharmacy leadership position. The finding of aspect before handling the leader position shower very low, for instance, less than the pharmacist did not receive pharmacy administration courses or training program before stated with position, or even general management education courses. Also, half of the leaders did not take any orientation program while handing the position, or they did not receive an endorsement from the previous manager 


\begin{tabular}{|c|c|c|}
\hline & Response N & Response \% \\
\hline Yes & 21 & $32.31 \%$ \\
\hline No & 44 & $67.69 \%$ \\
\hline \multicolumn{3}{|c|}{ Answered: 65 and skipped 5} \\
\hline \multicolumn{3}{|c|}{ The percentages incremental of salary of current position } \\
\hline $1-5 \%$ of salary & 11 & $15.71 \%$ \\
\hline $6-10 \%$ of salary & 6 & $8.57 \%$ \\
\hline $11-15 \%$ of salary & 2 & $2.86 \%$ \\
\hline $16-20 \%$ of salary & 4 & $5.71 \%$ \\
\hline$>20 \%$ of salary & 2 & $2.86 \%$ \\
\hline Nothing & 45 & $64.29 \%$ \\
\hline Other (please specify) & 3 & $15.71 \%$ \\
\hline Answered & 70 & \\
\hline Skipped & 0 & \\
\hline \multicolumn{3}{|c|}{ Are you planning to change or quit from your current position } \\
\hline Yes & 29 & $43.28 \%$ \\
\hline No & 14 & $20.90 \%$ \\
\hline I did not decide yet & 24 & $35.82 \%$ \\
\hline
\end{tabular}

or leader. Those factors are significant to start or complete the pharmacy work may lead the repetition of the work, starting from zero points, and loss of the time. Those factors absent because the $\mathrm{MOH}$ does not have the leadership performance organization including Pharmacy leadership. The results are difficult to compare with it most of the investigation not reported like those aspects. Most of the leaders gained the skills of leadership from life experience not organized manner; the results are higher than that reported by Pollard, SR et. al. ${ }^{[19]}$ In the USA, there are many of systemic and organized pharmacy leadership programs than in our country, and most of the leaders gained the pharmacy leadership through their practice life. Thus, that is leading to a lot of changes and resistance during the implementation of any new program in the pharmacy practice. Also, many discrepancies with the management of pharmacy staff. Most of the pharmacy leaders missed the marketing skills and negotiating skills that have reflected the pharmacist position not appropriate in the healthcare $\mathrm{MOH}$ hospital or organization. The one-third responders stated there no advantage of handing leader in the pharmacy practice with more half of them had the significant advantages the big responsibility with a high workload. Also, two third of them do have incremental in the salary. Those entire factors lead the pharmacist not to be leaders with a one-fifth wish to change or quit the position, and one third did not decide that. That reflected very badly of pharmacy leadership in the current situation. The complete revised of pharmacy leadership with the regular survey is highly recommended.

\section{CONCLUSIONS}

The pharmacy leadership is an appropriate situation in Ministry of Health organizations in the Kingdom of Saudi Arabia. The education and training were inadequate for pharmacy leaders. Most of the leadership position had many disadvantages with low advantages and the majority of pharmacist wish to change their position or quit the job at healthcare organizations in the Kingdom of Saudi Arabia.

\section{ACKNOWLEDGEMENT}

None

\section{CONFLICT OF INTEREST}

None

\section{SOURCE OF SUPPORT}

None

\section{ABBREVIATION USED}

KSA: Kingdom of Saudi Arabia, MOH: Ministry of Health.

\section{REFERENCES}

1. Zilz DA, Woodward BW, Thielke TS, Shane RR, Scott B. Leadership skills for a high-performance. Am J Heal Pharm. 2004;61(61):2562-74.

2. White SJ. Effective Pharmacy Department Leadership. Hosp Pharm. 2007;42(1):77-9.

3. Tsuyuki RT, Schindel TJ. Changing pharmacy practice: The leadership challenge. Can Pharm J. 2008;141(3):174-80.

4. Zellmer WA. Pharmacy Vision and Leadership : Revisiting the Fundamentals. Pharmacotherapy. 2008;28(12):1437.

5. Steve Acres et. al. Leadership Competency Framework for Pharmacy Professionals. Royal Pharmaceutical Society, Great Britain. 2010.

6. Khan MU, Hassali MA, Ahmad A, Elkalmi RM, Zaidi ST, Dhingra S. Perceptions and practices of community pharmacists towards antimicrobial stewardship in the state of Selangor, Malaysia. PloS one. 2016;11(2):e0149623.

7. Rafi MS, Naqvi SB, Khan MU, Fayyaz M, Ashraf N, Khan MA, et al. Evaluation of Potential Drug-Drug Interactions with Antidepressants in Two Tertiary Care Hospitals. JCDR. 2015;9(7):FC05.

8. Alomi YA. National Pharmacy Administration Programs at Ministry of Health in Saudi Arabia. BAOJ Pharm Sci. 2015;1(9).

9. Alomi YA, Alomi AY, Pharm B, Clin Pharm M. A new Guidelines on Hospital Pharmacy Manpower in Saudi Arabia. J Pharm Pract Community Med. 2016;2(2)

10. Alomi YA. Primary Care Center Pharmacy Manpower New Guidelines in Saudi Arabia. J Pharmacol Clin Res. 2016;1(1).

11. Alomi YA. National Primary Care Pharmacist Competency System at $\mathrm{MOH}$ in Saudi Arabia. JPharm Pharm Sci. 2016;1(4):1-5.

12. Alomi YA. Patient satisfaction of pharmaceutical care system at Ministry of Health in Saudi Arabia. BAOJ Pharm Sci. 2016;2:19.

13. Gouveia WA, Talbert RL, Hackner D, Miller WA. Pharmacy Management. The McGraw-Hill Companies. 2009.

14. Holdford D and BT. Introduction to Hospital and Health-System Pharmacy Practice. 2010.

15. Brown TR. Handbook of Institutional Pharmacy Practice. American Society of Health-System Pharmacists. 2006.

16. Whalley BJ. Foundation in pharmacy practice. 2008;212.

17. Stephens M. Hospital pharmacy. Pharmaceutical Press, editor. 2011.

18. Louie C, Mertz E, Penfil B, O'Neil E. A pharmacy leadership action study. J Am Pharm Assoc Japha. 2009;49(1):98-104.

19. Pollard SR, Clark JS. Survey of health-system pharmacy leadership pathways. Am J Heal Pharm. 2009;66(10):947-52.

20. White SJ, Enright SM. Is there still a pharmacy leadership crisis? A seven-year follow-up assessment. Am J Heal Pharm. 2013;70(5):443-7.

21. Traynor AP, Janke KK, Sorensen TD. Using personal strengths with intention in pharmacy: Implications for pharmacists, managers, and leaders. Ann Pharmacother. 2010;44(2):367-76.

22. Yuan C-C, Lo S-H. Relationship Among Team Temporal Leadership, Competency, Followership, and Performance in Taiwanese Pharmaceutical Industry Leaders and Employees. J Career Dev. 2016;(169):1-12.

23. Intergage Consulting Group. Toward an Optimal Future: Priorities for Action Research Report 2 Pharmacy Thought Leadership Summit @BULLET Research Report. Canadian Pharmacist Association. 2016. 
Pharmacy leadership and practice management

24. Janke KK, Traynor AP, Boyle CJ. Competencies for student leadership development in doctor of pharmacy curricula to assist curriculum committees and leadership instructors. Am J Pharm Educ. 2013;77(10):222.

25. Cho JC, Girnys JP. Preceptor Development Series National Survey Regarding the Importance of Leadership in PGY1 Pharmacy Practice Residency Training. Hosp Pharm [Internet]. 2015;50(11):978-84.

26. Feller TT, Doucette WR, Witry MJ. Assessing opportunities for student pharmacist leadership development at schools of pharmacy in the United States. Am J
Pharm Educ. 2016;80(5):79.

27. Moore RJ, Ginsburg DB. A Qualitative Study of Motivating Factors for Pharmacy Student Leadership. Am J Pharm Edu. 2017;81(6):1-8.

28. 360 Degree Feedback Items List. Available from: https://hr-survey. com/360FeedbackltemsList.htm.

29. Ministry of Health. An Achievements 2013. $1^{\text {st }}$ Ed. Riyadh, Saudi Arabia: Ministry of Health, Saudi Arabia. 2011;132-5.

Cite this article as: Alomi YA, Albaz MA, AlMuhraj WF, AlKharji MY, Alshuraym NR. National Survey of Pharmacy Leadership at Ministry of Health in Saudi Arabia: Practice Management. J Pharm Pract Community Med. 2018;4(1s):S73-S8. 